\title{
A moreninha e a tradição cômica do Romantismo brasileiro
}

\author{
Maria Cecília Boechat \\ Universidade Federal de Minas Gerais
}

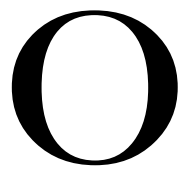

exercício do humor no Romantismo brasileiro tem sido reconhecido e estudado nas suas manifestações poéticas, principalmente no que diz respeito às obras de Álvares de Azevedo e Bernardo Guimarães. ${ }^{1}$ Pouco se falou, entretanto, das formas de humor cultivadas pela prosa. É curioso, pois a tradição cômica no romance parece ter sido inaugurada no momento mesmo em que se reconhece a existência de uma prosa brasileira, em $A$ moreninha, publicado em 1844, tendo tido, inclusive, papel fundamental para esse reconhecimento.

O que se afirma aqui não constitui, porém, novidade: a presença do humor como traço distintivo da obra romanesca de Joaquim Manoel de Macedo já foi sugerida por Antonio Candido.

Na Formação da Literatura Brasileira, Antonio Candido identifica, na obra de Macedo, uma espécie de binomia: de um lado, a recorrência ao "fantasioso folhetinesco" e ao exagero sentimentalista, que tanto agradava ao público;e, por outro, a exploração de um tipo de "realismo pequeno" ou "miúdo", para o qual contribuiria sua "veia cômica" e que estaria ligado a uma certa "vocação coloquial" do romancista:

A vocação coloquial desperta o interesse pelo mundo circundante, onde se vão buscar os elementos de conversa; desperta acuidade para os pequenos casos, os pormenores expressivos e menos aparentes, que

\footnotetext{
${ }^{1}$ Cf., especialmente, CAMILO, Vagner. Risos entre pares: poesia e humor românticos. São Paulo: EDUSP;FAPESP, 1997.
} 
por vezes definem melhor a natureza das ações. Determina, por fim, a simplicidade e a familiaridade do estilo. ${ }^{2}$

Os efeitos dessa vocação coloquial funcionariam como um corretivo "à grandiloqüência e gigantismo dos românticos", constituindo, então, para Cândido, tanto a qualidade quanto o defeito do romancista: pois justamente o que marcaria a sua diferença em relação aos modelos folhetinescos imporia uma inevitável mediocridade, ou banalização, conseqüente da "fidelidade a um meio social acanhado". O uso da veia cômica sofreria o mesmo limite:

O pequeno-realismo exprime se exprime, por exemplo, com maior pureza na veia cômica, entremeada por toda a sua obra. Ele adora a piada, a alusão engraçada, feito para o riso franco das rodas masculinas, exprimindo a vulgaridade do meio que retratou e fora estabilizado pelo período sobre as ruínas de uma aristocracia incipiente e mais refinada, devida a um quarto de século de vida palaciana, bruscamente interrompida pelo impulso democrático posterior ao 7 de Abril. Só numa sociedade bastante chucra poderiam ter bom curso suas chalaças, que ultrapassavam a vulgaridade, indo não raro à rasgada grosseria. Sirva de exemplo a graçola de Augusto, n'A moreninha, preparada com delícias pelo autor na cena entre ele e D. Violante[... $]^{3}$

O acerto do crítico é grande: de fato, o coloquialismo e o "pequeno realismo" do romance parecem ter sido fundamentais para o seu acolhimento e reconhecimento pelo público como sendo este o "primeiro romance brasileiro". A tradição crítica do romance já mostrou com eficiência a relação entre esses elementos e a popularidade do romance, indicando como fator decisivo essa facilidade com que o brasileiro identifica traços da sociedade da época. Nesse sentido, é importante ressaltar a diferença estabelecida por $A$ moreninha em relação ao restante da obra do próprio Macedo, ela mesma muito marcada pelo elemento folhetinesco do excesso de peripécias. Excesso que torna também grandiloqüente - distante e artificial - a narrativa de O filho do pescador, romance tantas vezes chamado a competir com o de Macedo pela primazia de nossa brasilidade literária. Como notam Lajolo e Zilberman:

\footnotetext{
${ }^{2}$ CANDIDO, 1981. p. 138.

${ }^{3}$ CANDIDO, 1981, p. 142.
} 
Se lembrarmos que O filho do pescador, obra de Teixeira e Souza publicada um ano antes, em 1843, é um romance pesado, enovelado em intrigas que se imbricam, com assassinatos e falsas identidades por tempero, A moreninha parece um hausto de ar puro num aposento fechado. A ligeireza do enredo, todo passado na aprazível ilha de..., evita agilmente os escombros do dramalhão e condiz bem com os ventos de modernidade que começam a soprar no Brasil dos idos de 40 do século [XIX]. ${ }^{4}$

O que parece questionável, porém, é a atribuição desse caráter do romance a um mero mecanismo de reflexo, seja de uma sociedade, seja de um autor ingênuos. Assim, o que tem sido visto como limitação pode bem ser uma estratégia usada consciente e intencionalmente pela narrativa.

Nessa perspectiva, releia-se passagem do texto (no capítulo XXII), em que a própria narrativa, de modo irônico, chama a atenção para o uso do sentimentalismo romântico. Trata-se de comentário feito aos males de amor que Augusto sofre no Rio de Janeiro, impedido que está por seu pai - zeloso pelos estudos do filho - de retornar à ilha. Na mesma ocasião, sofre Carolina, sem saber dos motivos da ausência de Augusto. Comenta então o narrador:

Os nossos amantes acabavam de chegar ao sentimental, e com seu sentimentalismo estavam azedando a vida dos que lhes queriam bem. Os namorados são semelhantes às crianças: primeiro divertem-nos com suas momices, depois incomodam-nos choramingando. (p. 256)

O comentário ilumina, assim, também a estrutura do romance, efetivamente dividido em duas partes: até então, o enredo ligeiro, todo ambientado na ilha, desenvolve-se em torno de episódios da vida juvenil, compondo a "amena superficialidade" do romance, já constatada por Antonio Candido. Mas que não é, de forma alguma, escamoteada pelo narrador, que comenta, por exemplo, acerca de cena protagonizada por Carolina e Augusto - em que essa superficialidade chega ao paroxismo da infantilização: "o amor está fazendo um estudante de quinto ano de

\footnotetext{
${ }^{4}$ LAJOLO e ZILBERMAN, São Paulo: 1991. p. 115.
} 
medicina passar um dia brincando de bonecas." ${ }^{5}$ A partir do capítulo XXII, começam os sofrimentos dos protagonistas. Nada, entretanto, de grandes dramas: por um lado, o desvelo do pai do rapaz foge inteiramente aos modelos dos obstáculos - sociais ou existenciais - da literatura romântica; por outro, o narrador mantém distância do "drama" vivido pelos personagens. Mais uma vez, o capítulo XXII é exemplar, trazendo, inclusive, uma peculiar teoria do amor. Na passagem citada anteriormente, os namorados foram comparados a crianças. A narrativa insiste, infantilizando o próprio sentimento amoroso:

(...) o amor é um menino doidinho e mal-criado que, quando alguém intenta refreá-lo chora, escarapela, esperneia, escabuja, belisca e incomoda mais que solto e livre. (p. 252)

$\mathrm{Na}$ cena que se segue - Augusto, trancafiado no quarto pelo pai, se desespera ao pensar nos sofrimentos de Carolina - coerentemente transfere a imagem para o protagonista:

Aqui, foi o nosso estudante às nuvens; saltou exasperado fora do leito em que se achava deitado, passeou a passos largos por seu quarto, acusou a crueldade dos pais, experimentou se podia arrombar a porta, fez mil planos de fuga, esbravejou, escabelou-se e, como nada disso lhe valesse, atirou com todos os seus livros para baixo da cama e deitou-se de novo, jurando que não havia de estudar dois meses. Carrancudo e teimoso, mandou voltar o almoço, o jantar e a ceia que lhe trouxeram, sem tocar num só prato; e sentindo que seu pai abria a porta do quarto, sem dúvida para vir consolá-lo e dar-lhe salutares conselhos, voltou o rosto para a parede e principiou a roncar como um endemoninhado. (p. 253)

Assim, apenas após ter rebaixado nosso herói juvenil à imagem infantil é que a narrativa retoma o modelo romântico tradicional, revestindo-o da aura melancólica. Após uma noite de amargor, reencontramos Augusto debilitado, sendo já atendido por um médico.

5 MACEDO, J. M. de. A moreninha. Edição crítica de Tânia Serra. Rio de Janeiro: Lacerda Ed., 1997. p. 247. As citações foram retiradas desta edição e passarão a ser indicadas pelo número das páginas, entre parênteses, no corpo do texto. 
A enfermidade de Augusto não cedeu, porém, com tanta facilidade (...) uma mudança apenas se operou: a exacerbação foi seguida de um abatimento e prostração de forças notável; sua paixão, que também se desenhava no ardor dos olhares, na viveza das expressões e na audácia dos pensamentos, tomou outro tipo: Augusto tornou-se pálido, sombrio e melancólico; horas inteiras se passavam sem que uma só palavra fosse murmurada por seus lábios, prolongadas insônias eram marcadas minuto a minuto por dolorosos gemidos, e seus olhos, amortecidos, como que obsequiavam a luz quando por acaso se entreabriam. (p.255)

Carolina, por seu turno, na ilha apresentava sintomas semelhantes, e a "morena travessa" vai também se entristecendo, inconsolável, adquirindo, assim, algo da imagem ideal da heroína romântica típica.

A mudança das personagens prepara a cena principal do romance, em que o segredo da narrativa - Augusto e Carolina são as mesmas crianças que haviam jurado amor eterno nas cenas iniciais - será revelado. Todo o capítulo XXIII é reservado a essa revelação, ponto alto do entrecho sentimentalista.O diálogo é longo, explorando o conflito dos protagonistas. Enquanto eles sofrem, porém, a narrativa mantém o distanciamento no tratamento da cena. "A cena estava tornando-se patética", anota o narrador, fazendo com que também o leitor se dê conta do excesso sentimentalista e perceba o ridículo da cena.

Essa notação, por si só explícita e eficaz, sendo feita exatamente no clímax do romance, momento máximo do conflito e, ao mesmo tempo, de sua dissolução, impede, ainda, uma leitura mais séria, ou "adulta" do tema desenvolvido pelo romance. Pois, por incrível que pareça, ele tem lá suas reverberações mais profundas: o tema do amor infantil reencontrado, mas não imediatamente reconhecido, trata, a seu modo, do tema mais profundo do amor como ideal ou ilusão irrealizável. Só nesta perspectiva ganha sentido o diálogo do capítulo XXIII, que passamos a acompanhar:

- Oh! Pois bem, disse [Carolina]; vá ter com sua antiga desposada, repita-lhe o que acaba de dizer, e, se ela ceder, se perdoar, volte que serei sua...esposa" diz Carolina.

Ao que, sem compreender bem, pergunta Augusto:

“- Sim...eu corro....Mas, meu Deus, onde poderei achar essa moça a quem não tornei a ver, nem poderei conhecer? Onde meu Deus?... onde?... 
Só então tudo é esclarecido:

- Espere, tornou D. Carolina, escute, senhor. Houve um dia, quando minha mãe era viva, que eu também socorri a um velho moribundo. Como o senhor e a sua camarada, matei a fome de uma família....em sinal de reconhecimento também este velho me fez um presente(...) eu cosi essa relíquia dentro de um breve(...) trago-o sempre comigo; eu lho cedo... tome o breve, descosa-o, tire a relíquia e a mercê dela encontre sua antiga amada. Obtenha o seu perdão e me terá por sua esposa. (p. 268)

Finalmente, o rapaz cai a seus pés, e o desfecho previsível se completa. A insistência de Carolina no pedido de perdão, que paradoxalmente só pode ser dado por ela mesma, merece, porém, alguma reflexão. Ora, desde o início da narrativa, Augusto fora caracterizado como um jovem inconstante nos amores, o que ele justificara justamente por sua constância em relação ao juramento de infância. Assim, Augusto não pode amar... porque ama; e ama um ideal perdido. Eis aqui um problema para uma poética ingênua do amor romântico: ainda que reencontrada a menina, ela, e nem mesmo o próprio menino, já serão os mesmos ( não é fortuito, portanto, que nossos protagonistas não se reconheçam quando se reencontram). O amor dos jovens Carolina e Augusto, embora se legitime justamente em nome do amor das crianças Carolina e Augusto, constitui ao mesmo tempo a sua traição: o "amor verdadeiro" é traição ao "amor verdadeiro". Por isso é que Carolina criança tem, antes de tudo, de perdoar a Augusto. E, não menos importante, à própria Carolina jovem. Assistimos, assim, a um desdobramento das personagens que retoma, também a seu modo, despretensiosamente, a concepção do sujeito cindido, tão cara aos romantismos mais filosóficos...

Vê-se, assim, que o romance também pode ser lido de uma forma mais séria do que tem sido hoje possível. De qualquer modo, é um tipo de leitura que parece inadequado em relação ao tom do próprio romance. É como se a notação do narrador alertasse: "a cena [da análise] estava se tornando patética..." Sensato parece ser, então, reler o romance tal como se lê um texto escrito, como diria Brás Cubas, "com a pena da galhofa".

O que se tira da profundidade, porém, deve ser dado à "frivolidade" bem humorada do romance, reconhecendo, em sua veia cômica, uma posição consciente em relação à tradição romântica européia. Nessa perspectiva, A moreninha constituiria uma apropriação irônica dos modelos sentimentalistas, só chegando a poder compor uma "poética do 
sentimento" - a partir da qual tem sido interpretado - porque sabe rir de sua própria "ingenuidade". Reconhecer essa dimensão do romance, entretanto, exige que o elemento cômico seja também reconhecido como mais do que um elemento superficial da trama: como uma estratégia eficiente e legítima da ironia romântica, tal como seria ativada pela geração poética posterior.

\section{Referências Bibliográficas}

MACEDO, Joaquim Manoel de. A moreninha. Rio de Janeiro: Lacerda Editores: 1997.

LAJOLO e ZILBERMAN. A leitura rarefeita. São Paulo: Brasiliense: 1991.

CANDIDO, Antonio. Formação da literatura brasileira. Belo Horizonte, Itatiaia: 1981. vol. II.

CAMILO, Vagner. Risos entre pares: poesia e humor românticos. São Paulo: EDUSP; FAPESP, 1997.

\section{Resumo}

Proposta de leitura do romance A moreninha, de Joaquim Manuel de Macedo, relacionando o uso de elementos cômicos - tais como o exagero sentimentalista e a infantilização dos protagonistas - à ironia romântica.

\section{Résumé}

Lecture du roman $A$ moreninha, de Joaquim Manuel de Macedo, en rapportant l'usage des éléments comiques - tels que l'éxagération sentimentaliste e l'infantilisation des protagonistes - à l'ironie romantique. 